\title{
STATIC STRUCTURAL ANALYSIS OF BIMETALLIC PISTON USING DIFFERENT MATERIAL COMBINATIONS
}

\author{
Pepakayala.Varaprasad ${ }^{1} \&$ Kodimela.Keerthi ${ }^{2}$
}

ABSTRACT- In today's world scenario, there is tremendous development in the field of automobile and every day, there is a new invention to do better out transport facility. Also company may concentrated on very important fact, service after sale it is consider spinal code in the field of automobile. Most of the company may spend their $50 \%$ of their income on research and development to make their vehicle better. Previously this task is very expensive in absence of recent technology, for testing and design like CAD/CAM and the analysis software like Ansys software, the prediction is very difficult about any product. Also CFD play major role for the aerodynamic designing for the automobile. Using Different CAD/CAM software one can design the product as per the requirement, and can also manufacture easily on CNC machine. This project work is based on bimetallic component used in automobile; there are lots of bimetallic components used in automobile application. In this case, we are studying the scope of different material combinations for manufacturing bimetallic pistons. In these study two different models of pistons - Regular and Bi-Metallic are studied under engine operating conditions with different material combinations, for model Development we use Catia V5 and for Analysis we use Ansys 15.0

Key words - Bimetallic Materials, Automobile, ansy

\section{INTRODUCTION}

\section{Internal Combustion Engine}

The internal combustion engine is an engine in which the burning of a fuel occurs in a confined space called a combustion chamber. This exothermic reaction of a fuel with an oxidizer creates gases of high temperature and pressure, which are permitted to expand. The defining feature of an internal combustion engine is that useful work is performed by the expanding hot gases acting directly to cause movement, for example by acting on pistons, rotors, or even by pressing on and moving the entire engine itself.

Piston

Pistons are usually equipped with piston rings. These are circular metal rings that fit into grooves in the piston walls and

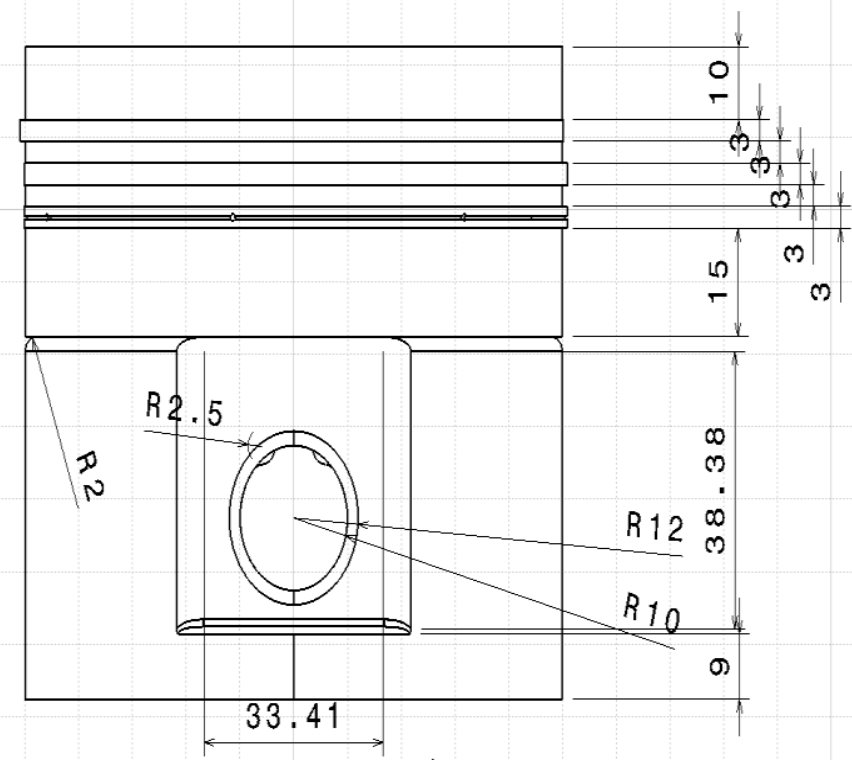

\footnotetext{
${ }^{1}$ Department of mechanical Engineering, Aditya College of Engineering and Technology, Surampalem, A.P, India

${ }^{2}$ Department of mechanical Engineer, Aditya College of Engineering and Technology, Surampalem, A.P, India
} 
assure a snug fit of the piston inside the cylinder. They help provide a seal to prevent leakage of compressed gases around the piston and to prevent lubricating oil from entering the combustion chamber.

\section{Bimetals}

Bimetal refers to an object that is composed of two separate metals joined together. Instead of being a mixture of two or more metals, like alloys, bimetallic objects consist of layers of different metals. Tri-metal and tetra-metal refer to objects composed of three and four separate metals respectively.

\section{Drafting}

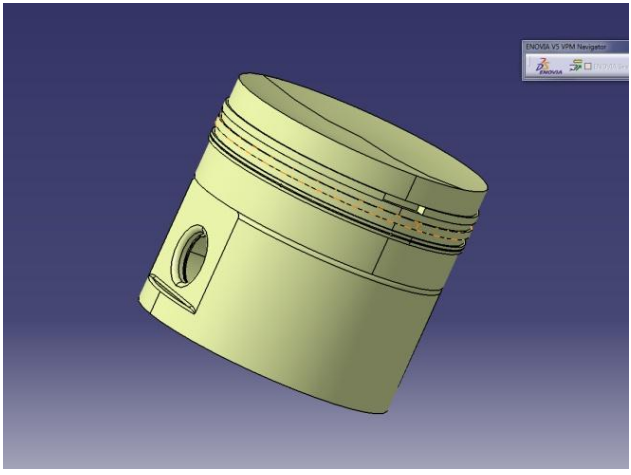

MODELLING

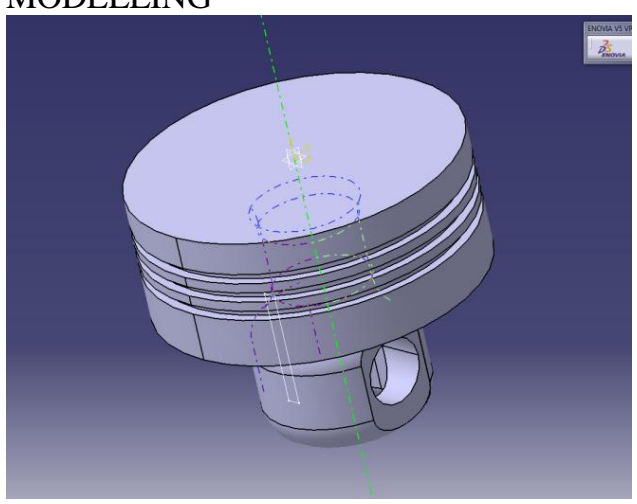

3D Model of Piston

ANALYSIS

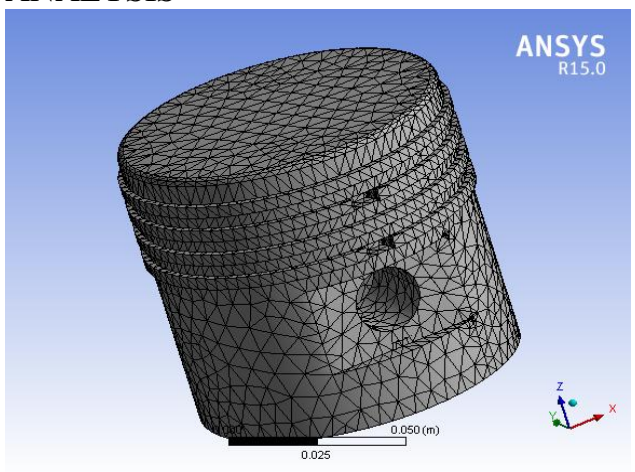

MESHED MODEL
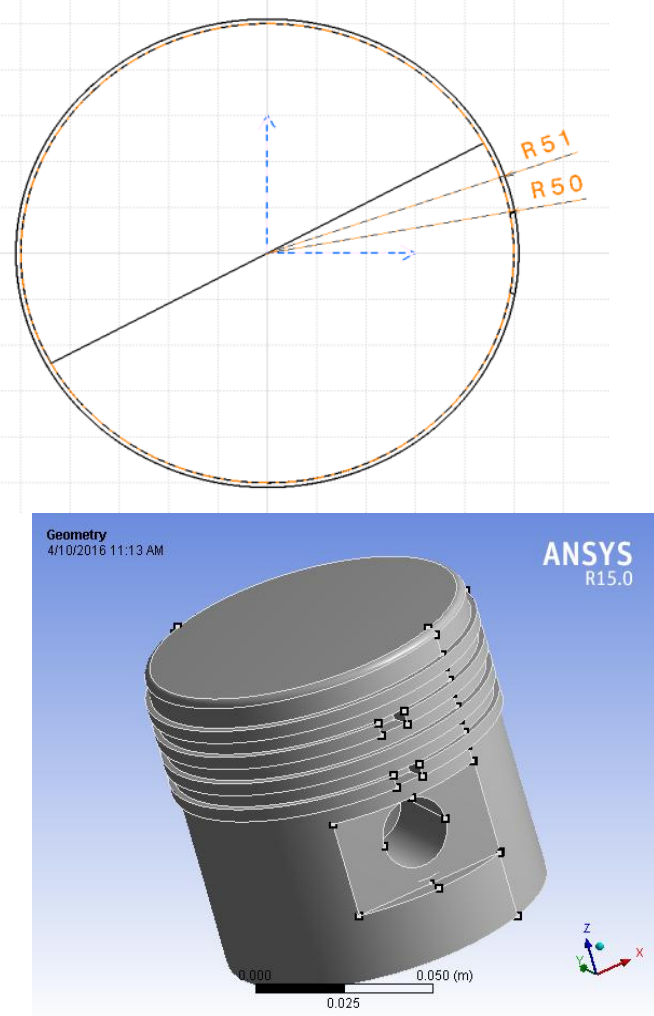

\section{GEOMETRY}

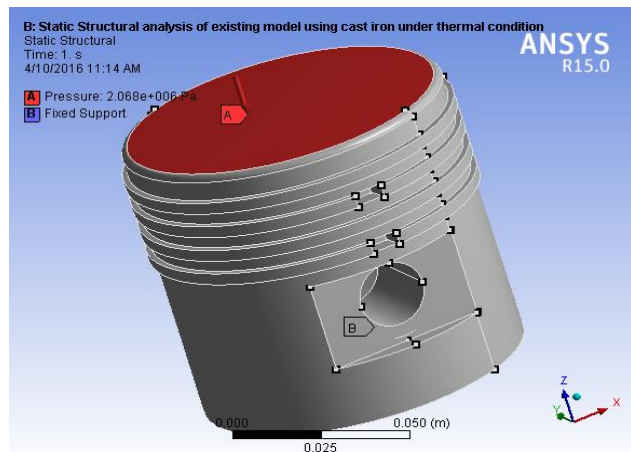

PRESSURE INPUT 


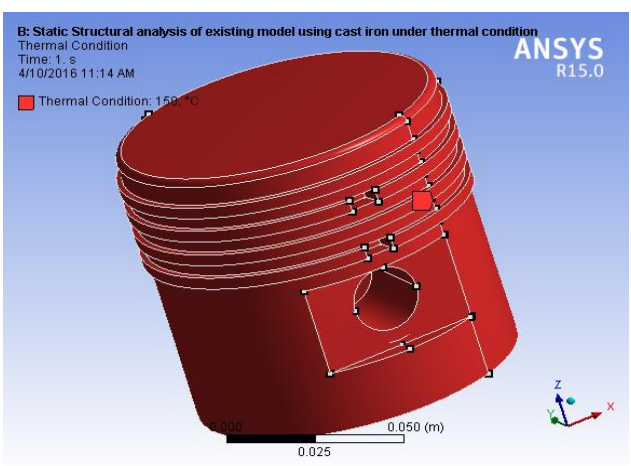

THERMAL CONDITIONS

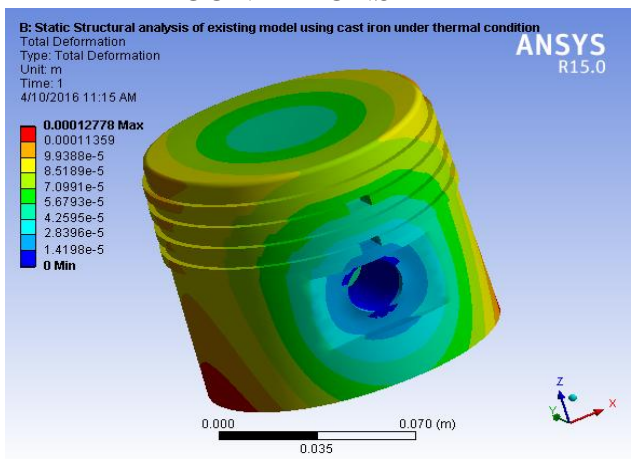

TOTAL DEFORMATION

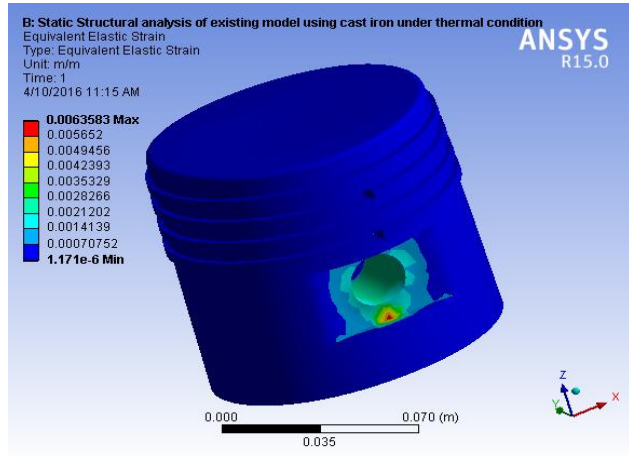

\section{STRAIN}

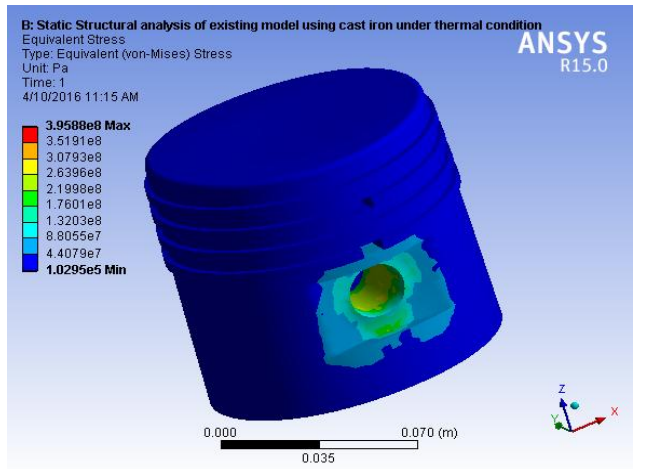

STRESS

\section{REPORTS}

\begin{tabular}{|l|l|l|l|l|l|l|l|}
\hline \multirow{2}{*}{$\begin{array}{l}\text { Existing } \\
\text { model }\end{array}$} & \multicolumn{5}{|l|}{ Total Deformation $(\mathrm{m})$} & \multicolumn{2}{l|}{$\begin{array}{l}\text { Equivalent } \\
(\mathrm{m} / \mathrm{m})\end{array}$} \\
\cline { 2 - 7 } & Minimum & Maximum & Minimum & Maximum & Minimum & Maximum \\
\hline Cast Iron & 0 & $1.28 \mathrm{E}-04$ & $1.17 \mathrm{E}-06$ & $6.36 \mathrm{E}-03$ & $1.03 \mathrm{E}+05$ & $3.96 \mathrm{E}+08$ \\
\hline Titanium & 0 & $1.07 \mathrm{E}-04$ & $6.45 \mathrm{E}-07$ & $5.83 \mathrm{E}-03$ & 61905 & $3.38 \mathrm{E}+08$ \\
\hline Aluminium & 0 & $2.74 \mathrm{E}-04$ & $2.97 \mathrm{E}-06$ & $1.21 \mathrm{E}-02$ & $1.49 \mathrm{E}+05$ & $5.79 \mathrm{E}+08$ \\
\hline Zirconium & 0 & $6.33 \mathrm{E}-05$ & $5.92 \mathrm{E}-07$ & $3.32 \mathrm{E}-03$ & 91460 & $3.79 \mathrm{E}+08$ \\
\hline
\end{tabular}

Table-1: Table showing the structural analysis results for existing model

\begin{tabular}{|l|l|l|l|l|l|l|}
\hline \multirow{2}{*}{$\begin{array}{l}\text { Bimetallic } \\
\text { model }\end{array}$} & \multicolumn{2}{|l|}{ Total Deformation (m) } & \multicolumn{2}{l|}{$\begin{array}{l}\text { Equivalent } \\
\text { Strain (m/m) }\end{array}$} & \multicolumn{2}{l|}{$\begin{array}{l}\text { Equivalent } \\
\text { Mises) Stress (Pa) }\end{array}$} \\
\cline { 2 - 8 } & Minimum & Maximum & Minimum & Maximum & Minimum & Maximum \\
\hline Cast Iron & 0 & $1.14 \mathrm{E}-04$ & $-1.88 \mathrm{E}-05$ & $8.36 \mathrm{E}-03$ & 438.44 & $1.50 \mathrm{E}+09$ \\
\hline Titanium & 0 & $1.02 \mathrm{E}-04$ & $6.97 \mathrm{E}-09$ & $8.59 \mathrm{E}-03$ & 371.84 & $1.50 \mathrm{E}+09$ \\
\hline Aluminium & 0 & $2.05 \mathrm{E}-04$ & $8.64 \mathrm{E}-09$ & $9.82 \mathrm{E}-03$ & 289.63 & $1.50 \mathrm{E}+09$ \\
\hline
\end{tabular}




\begin{tabular}{|l|l|l|l|l|l|l|}
\hline Zirconium & 0 & $2.05 \mathrm{E}-04$ & $4.82 \mathrm{E}-09$ & $8.00 \mathrm{E}-03$ & 362.6 & $1.50 \mathrm{E}+09$ \\
\hline
\end{tabular}

Table-2: Table showing the structural analysis results for bimetallic model

\section{CONCLUSION}

\section{Future Scope}

The study on this project is done using only four materials i.e., Cast iron, Titanium, Aluminum alloy and Zirconium. So, study can be further extended by considering different materials for the study. Also, the bimetals used in this study can be replaced by different Metal matrix composites.

\section{REFERENCES}

[1] Pistons and engine testing by Mahle GmbH, Springer Science \& Business Media, 26-Jan-2013

[2] Materials Selection in Mechanical Design by Michael F. Ashby, Butterworth-Heinemann, 29-Oct-2010

[3] Engineering Fundamentals of the Internal Combustion Engine by Willard W. Pulkrabek, Prentice Hall, 1997

[4] Worldwide Guide to Equivalent Nonferrous Metals and Alloys by Fran Cverna, ASM International, 01-Jan-2001

[5] Zirconium: International Strategic Minerals Inventory Summary Report, DIANE Publishing Company, 01-Apr-1994

[6] O.S. Lee, HongMin Kim and HeyBin Choi., "High temperature dynamic deformation of aluminum alloys using SHPB by mechanical science and technology", 2011.

[7] DongfangBai, "Solving Piston Secondary Motion of Internal Combustion Engines", Sloan Automotive Laboratory, Massachusetts Institute of Technology.

[8] Hirotaka Murakami, Narutake Nakanishi, Naoto Ono and Tomoharu Kawano., "New Three dimensional piston secondary motion analysis method coupling structure analysis and multi body dynamics analysis" JSAE 20119559 / SAE 2011-32-0599.

[9] Z. Geng, J.Chen, "Investigation into piston slap induced vibration for engine condition simulation and monitoring", Journal of Sound and Vibration 282, 2005

[10] P. Gustof, A. Hornik., "The influence of the engine load on value and temperature distribution in the piston of the turbocharged Diesel engine", Journal of Achievements in Materials and Manufacturing Engineering. AMME, Received 16.02.2009; published in revised form 01.08.2009.

[11] ZuoqinQian, Honghai Liu, Guangde Zhang and David J., "Temperature Field Estimation for the Pistons of Diesel Engine 4112" Journal of Wuhan Technology University, 2005.

[12] Dr. S.N.Kurbet and R.Krishnakumar ., "A Finite Element study of Piston Tilt effects on Piston Ring Dynamics in IC Engines", ProcInstnMechEngrs (IMECHE) Part K.2004, pp 107-117”.

[13] Mahdi Hamzwhei and ManochehrRashidi., "Determination of Piston and Cylinder Head Temperature Distribution in a 4 - Cylinder Gasoline Engine at Actual Process", Proceedings of the 4th WSEAS Int. Conf. on heat transfer, thermal engineering and environment, Elounda, Greece, August 2006.

[14] C.D. Rakopoulos, G.C Mavropoulos., Experimental and theoretical study of the short term response temperature transients in the cylinder wall of a diesel engine at various operating conditions", Applied thermal engineering 24, 2004.

[15] Ali Sanli, Ahmet N Ozsezen, Ibrahim Kilicaslan., "The influence on engine speed and load on the heat transfer between gases and in cylinder walls at fired and motored conditions of an IDI diesel engine", Applied thermal engineering 28, 2008.

[16] Dr. Ahmed A, Dr. Basim., "Thermal effects on diesel engine piston and piston compression ring", Engineering and technology Journal, Vol. 27, No. 8, 2009. Books:

[17] V. Ganesan., "Internal combustion engines", Tata McGraw-Hill Publications.

[18] John.B. Heywoob.," Internal combustion engines: Applied Thermo sciences", John Wiley and Sons.

[19] P.K. Nag,"Engineering Thermodynamics", Tata McGraw-Hill Publications. 